\title{
Snapshot prediction of carbon productivity, carbon and protein content in a Southern Ocean diatom using FTIR spectroscopy
}

\author{
Olivia Sackett ${ }^{1,2}$, Katherina Petrou ${ }^{1}$, Brian Reedy ${ }^{3}$, Ross Hill ${ }^{4}$, Martina Doblin ${ }^{1}$, \\ John Beardall $^{5}$, Peter Ralph ${ }^{1}$ and Philip Heraud ${ }^{6}$ \\ ${ }^{1}$ Plant Functional Biology and Climate Change Cluster, Faculty of Science, University of Technology, Sydney, \\ New South Wales, Australia; ${ }^{2}$ School of Biological Sciences, Monash University, Melbourne, Victoria, \\ Australia; ${ }^{3}$ School of Chemistry and Forensic Science, University of Technology, Sydney, New South Wales, \\ Australia; ${ }^{4}$ Centre for Marine Bio-Innovation and Sydney Institute of Marine Science, School of Biological, \\ Earth and Environmental Sciences, University of New South Wales, Sydney, New South Wales, Australia; \\ ${ }^{5}$ Centre for Biospectroscopy and School of Biological Sciences, Monash University, Melbourne, Victoria, \\ Australia and ${ }^{6}$ School of Biological Sciences and Centre for Biospectroscopy, School of Chemistry, Monash \\ University, Melbourne, Victoria, Australia
}

\begin{abstract}
Diatoms, an important group of phytoplankton, bloom annually in the Southern Ocean, covering thousands of square kilometers and dominating the region's phytoplankton communities. In their role as the major food source to marine grazers, diatoms supply carbon, nutrients and energy to the Southern Ocean food web. Prevailing environmental conditions influence diatom phenotypic traits (for example, photophysiology, macromolecular composition and morphology), which in turn affect the transfer of energy, carbon and nutrients to grazers and higher trophic levels, as well as oceanic biogeochemical cycles. The paucity of phenotypic data on Southern Ocean phytoplankton limits our understanding of the ecosystem and how it may respond to future environmental change. Here we used a novel approach to create a 'snapshot' of cell phenotype. Using mass spectrometry, we measured nitrogen (a proxy for protein), total carbon and carbon-13 enrichment (carbon productivity), then used this data to build spectroscopy-based predictive models. The models were used to provide phenotypic data for samples from a third sample set. Importantly, this approach enabled the first ever rate determination of carbon productivity from a single time point, circumventing the need for timeseries measurements. This study showed that Chaetoceros simplex was less productive and had lower protein and carbon content during short-term periods of high salinity. Applying this new phenomics approach to natural phytoplankton samples could provide valuable insight into understanding phytoplankton productivity and function in the marine system.

The ISME Journal (2016) 10, 416-426; doi:10.1038/ismej.2015.123; published online 31 July 2015
\end{abstract}

\section{Introduction}

Each year, growth of marine phytoplankton produces $\sim 48.5 \times 10^{9}$ tonnes of organic carbon, roughly equivalent to terrestrial photosynthesis (Field et al., 1998). More than $40 \%$ of the marine primary production is attributed to diatoms, a group of silicifying microalgae (Nelson et al., 1995). In the Southern Ocean, massive diatom blooms occur on a seasonal basis, covering thousands of square kilometers (Blain et al., 2007), providing carbon,

Correspondence: P Heraud, School of Biological Sciences and Centre for Biospectroscopy, School of Chemistry, Monash University, Building 18 Clayton, Melbourne, Victoria 3008, Australia. E-mail: phil.heraud@monash.edu

Received 14 November 2014; revised 9 April 2014; accepted 9 June 2015; published online 31 July 2015 nutrients and energy to the Southern Ocean ecosystem (Bernard et al., 2012). Annual freezing and thawing of the Southern Ocean means that diatoms are subject to major fluctuations in physicochemical (salinity, temperature, nutrients and light) conditions. These seasonal fluctuations are known to stimulate changes in diatom phenotypes, such as photophysiology (Ralph et al., 2007), macromolecular composition (Mock and Hoch, 2005) and morphology (Morgan-Kiss et al., 2006). The ability to rapidly acclimate via phenotypic plasticity is essential for cells to satisfy physiological requirements and maximize fitness in variable environments. Antarctic diatoms have been shown to adjust their photophysiology to maximize photosynthesis for growth (Ralph et al., 2007; Petrou and Ralph, 2011) and vary their macromolecular pools to changing environmental conditions, increasing lipid concentrations 
for maintaining membrane structure and for energy storage (Mock and Kroon, 2002) or altering protein concentrations in response to osmoregulation and cryoprotection (Krell et al., 2008). Although speciesspecific data are scarce, increasing evidence suggests that phenotypic responses are highly variable within and between taxonomic groups (Petrou and Ralph, 2011; Petrou et al., 2011; Sackett et al., 2013).

Understanding phenotypic variation is of great importance, as the phenotypes of marine phytoplankton determine ocean biogeochemistry and the efficiency with which carbon, nutrients and energy are transferred to higher trophic levels (Hessen et al., 2004; Arrigo, 2005). In variable environments, such as those in the Southern Ocean, the caloric value of food can be of critical importance, in particular in winter when sunlight and food are scarce. For example, lipids, which are the most energy-rich macromolecule, are known to vary under different environmental conditions (Mock and Kroon, 2002); therefore, changes in macromolecular composition and energy partitioning in the cell will determine the nutritional value of the food and productivity of the entire food web (Diekmann et al., 2009). Quantifying a species' capacity for phenotypic variation can inform predictions of its ability to survive environmental change (Charmantier et al., 2008) and may provide insight into which species could dominate under future environmental conditions in the Southern Ocean, such as a reduction in sea-ice thickness, duration and extent. Investigating the phenotypic responses of organisms, using high-throughput, highdimensional methods, referred to as phenomics (Houle et al., 2010), may be particularly informative in the Southern Ocean ecosystem, where shifts in phytoplankton communities may occur in response to the recent rapid pace of environmental change (Ducklow et al., 2013) and could provide insight into which species will dominate under future environmental conditions.

Investigating the phenotypic responses of Southern Ocean organisms is of growing importance for furthering our understanding of ecosystem processes into the future. However, field-based phenotypic data are in short supply, largely because of the great expense associated with sample collection and the slow turnaround time between collection and analysis. Current methods for quantitative studies of phytoplankton phenotypes involve lengthy protocols and/or expensive analytical techniques. The use of ${ }^{14} \mathrm{C}$ involves phytoplankton being incubated under desired conditions and productivity determined by calculating the relative change in isotopic enrichment over a given period (typically 1-24 h). Although measuring incorporation of ${ }^{14} \mathrm{C}$ by the entire phytoplankton community is relatively rapid and inexpensive, the analysis of individual taxa within mixed natural samples is a time-consuming process (isolation and analysis of cells from individual taxa) and is impractical for high-throughput studies. In addition, the radioactivity of this isotope limits its application in the field (Hama et al., 1983). Methods based on ${ }^{13} \mathrm{C}$ avoid the use of radioactive isotopes; however, analysis can be relatively expensive. Regardless of the advantages and disadvantages of these two methods, a common limitation to both is that measurements need to be taken over time. This methodological limitation has resulted in a slow supply of phenotypic data relative to demand from research groups such as biogeochemical and ecosystem modelers (Carr et al., 2006; Graff et al., 2012).

Spectroscopic approaches offer substantial benefits over traditional methods, being inexpensive, quantitative, objective, rapid, high throughput, sensitive and inherently multivariate (Hirschmugl et al., 2005; Heraud et al., 2005, 2007a, 2008; Jebsen et al., 2012; Sackett et al., 2013). The use of spectroscopic techniques such as Raman and Fourier transform infrared (FTIR) spectroscopy in phytoplankton studies has been widely explored (Heraud et al., 2007b; Heraud et al., 2008; Domenighini and Giordano, 2009; Dean et al., 2012, 2010). These techniques involve irradiating a sample with specific wavelengths of light and measuring light scattering (Raman spectroscopy) or absorbance (FTIR spectroscopy) by the sample. The resulting spectra consist of absorbance bands associated with macromolecules that can be interpreted to reveal quantitative variations in cell phenotype in terms of physiology (Li et al., 2012), pigment content (Andreeva and Velitchkova, 2005) and macromolecular composition (Heraud, et al., 2007b). In a recent study, Jebsen et al. (2012) predicted growth rates from FTIR spectra of microalgal cells, showing that FTIR spectroscopy can provide a valuable alternative to time-series measurements for the collection of physiological rate data. Adopting this approach, here we develop a method to predict a number of phenotypic traits including rates of carbon production in phytoplankton cells.

Specifically, we combined ${ }^{13} \mathrm{C}$ mass spectrometry (quantitative elemental measurements) and FTIR microspectroscopy (rapid, high-throughput, semiquantitative, multivariate macromolecular measurements) to provide a quantitative and rapid approach for the collection of phytoplankton phenotypic data. Using mass spectrometry to build a calibration data set, we predict multiple phenotypic traits including cellular carbon and protein content, based on the FTIR spectra from intact C. simplex cells. We also use the predictive model to obtain rates of carbon productivity. This is the first study, to our knowledge, that demonstrates the derivation of carbon productivity from a measurement taken at a single time point, providing the first ever 'snapshot prediction' of phytoplankton carbon production rates. As these measurements are based on a single species of cultured alga, the ecological implications of the findings should be approached with caution. Notwithstanding, this study serves as a valuable and exciting proof-of-concept for future work. 


\section{Materials and methods}

Microalgal culturing and experimental conditions Cultures of the Antarctic diatom $C$. simplex were grown from isolated cells from the coastal waters of Antarctica, Prydz Bay (CS 624, Australian National Algae Culture Collection, CSIRO, Hobart, TSM, Australia) and maintained at $4{ }^{\circ} \mathrm{C}$ in filtered $(0.2 \mu \mathrm{m})$ natural Antarctic seawater (collected from $145.9^{\circ} \mathrm{S} 54.0^{\circ} \mathrm{S}, 72 \mathrm{~m}$, during SAZ-Sense (a study of the sensitivity of Sub-Antarctic Zone waters to global change, CSIRO), January-February 2007, RSV Aurora Australis) supplemented with F/ 2 nutrients. The experiment was conducted as described in Petrou et al. (2011). Briefly, cultures of $C$. simplex were grown in specially designed 1 liter glass culturing vessels in natural seawater (salinity 34) amended with F/2 nutrients (Guillard and Ryther, 1962) and maintained under continuous air bubbling at $4{ }^{\circ} \mathrm{C}$ on a $16: 8 \mathrm{~h}$ light:dark cycle at $50 \mu \mathrm{mol}$ photons per $\mathrm{m}^{2} \mathrm{~s}^{-1}$ (Grolux, GMT Lighting, Northmead, NSW, Australia). Cultures were maintained in exponential growth phase by diluting (up to $80 \%$ ) with fresh medium every $2-3$ days.

To initialize experimental treatments, cultures were concentrated by gentle vacuum filtering using $2 \mu \mathrm{m}$ polycarbonate membrane filters (Millipore, Billerica, MA, USA) and re-suspended in $\sim 150 \mathrm{ml}$ of medium in $250 \mathrm{ml}$ culture flasks at four different salinities $(31,34,55$ and $70( \pm 0.5, n=4)$. The salinity of the F/2 medium was adjusted either by the addition of MilliQ water or sodium chloride salt (Sigma, St Louis, MO, USA) and measured using a refractometer. Flasks were then assigned to three different temperature treatments $\left(-1.8^{\circ} \mathrm{C}, 2^{\circ} \mathrm{C}\right.$ and $\left.5{ }^{\circ} \mathrm{C}\left( \pm 0.3^{\circ} \mathrm{C}\right)\right)$, provided by temperature-controlled incubators. Cell cultures were given $72 \mathrm{~h}$ under their new conditions before subsamples were taken to assess their short-term responses to transient environmental conditions. Samples were analyzed spectroscopically for macromolecular composition and by mass spectrometry for cellular carbon $\left({ }^{12} \mathrm{C}\right.$ and ${ }^{13} \mathrm{C}$ ) and nitrogen content (see description below). Treatments were applied in quadruplicate, using a fully factorial design to capture a range of salinity and temperature regimes characteristic of the Southern Ocean annual freeze-thaw cycle, namely sea ice $\left(-1.8^{\circ} \mathrm{C}\right.$, salinity 70$)$, meltwater $\left(2^{\circ} \mathrm{C}\right.$, salinity 30$)$ and pelagic $\left(5^{\circ} \mathrm{C}\right.$, salinity 34$)$ conditions, respectively. Growth rates (doublings per day) were determined using in-vivo fluorescence measurements (Trilogy, Turner Designs Inc., Sunnyvale, CA, USA), where fluorescence was measured at the initial time point for the $72 \mathrm{~h}$ (T0) incubation and at the end of the incubations (T72). Chlorophyll $a$ concentration was used as a proxy for biomass, where relative fluorescence units were converted to chlorophyll $a$ concentration by a factor determined using a calibration standard (Wood et al., 2005). Rates were then calculated by taking the proportional rate of change in chlorophyll $a$ and multiplying it by natural log of 2 (0.6931).
FTIR spectroscopy for macromolecular 'snapshot' measurements

Approximately $15 \mathrm{ml}$ of cell suspension was filtered onto $1 \mu \mathrm{m}$ polycarbonate filter membrane (Millipore) using a hand-operated vacuum filter tower. Cells collected on the filter were then re-suspended in isotonic saline solution ( $\mathrm{NaCl}$ (Sigma) and MilliQ water) to wash the cells, to remove $F / 2$ medium, which contains compounds that can absorb infrared radiation and possibly confound the FTIR measurements (Heraud et al., 2007b). The saline solution was kept at the same temperature as the incubation temperature of the cells. This rinsing process was repeated three times for each replicate. To minimize the chance of spectral artifacts resulting from the use of transflection measurements, washed cells were deposited on Kevley MirrIR Low-e Microscope Slides (Kevley Technologies, Chesterland, OH, USA) using a Shandon Cytospin Centrifuge (Cytospin III, Thermo Fisher Scientific, Waltham, MA, USA) and immediately stored in a vacuum desiccator at room temperature until analysis (Heraud et al., 2007b; Cao et al., 2013). This method has been shown to result in cellular monolayers with homogenous thickness (Cao et al., 2013; Heraud and Wood, 2013) and therefore minimize issues related to the previously reported electric field standing wave effect (Bassan et al., 2009, 2013; Filik et al., 2012). Flow cytometry confirmed that minimal changes in cell forward scatter (proxy for size) occurred between treatment conditions (mean $\pm 5 \%$, data not shown), further reducing the likelihood of spectral artifacts, which have been shown to relate to differences in sample thickness (Heraud and Wood, 2013).

Spectral data were collected using a FTIR spectrometer (Digilab FTS 7000 Series) fitted with a UMA 600 Microscope and a mercury cadmium telluride detector cooled with liquid nitrogen (Agilent, Mulgrave, VIC, Australia). Spectral acquisition and instrument control were performed using Win-IR Pro software (Agilent). Spectra were acquired over the measurement spectral range 4000-800 $\mathrm{cm}^{-1}$. The microscope objective had a Plexiglas hood, which was purged with dehumidified air. The measurements were performed in the singlepoint mode, with the focal plane aperture of the FTIR microscope open, at a spectral resolution of $8 \mathrm{~cm}^{-1}$, with 256 scans co-added. The number of co-added scans was chosen as a good compromise between achieving spectra with good signal-to-noise characteristics and the rapid acquisition of data. FTIR spectral data were exported from Win-IR Pro for multivariate analysis using The Unscrambler X v 10.2 (CAMO, Oslo, Norway). An initial quality-control procedure was performed over the spectral range $3000-950 \mathrm{~cm}^{-1}$, where spectra with maximum absorbance $>0.85$, which resulted from spectral acquisition of regions of the sample where cells were clumped, were rejected. Spectra were then pre-processed taking the second derivative using the Savitzky-Golay algorithm with nine smoothing points and normalization using extended multiplicative signal correction. 
Calibration data for predictive models

Mass spectrometry was used to measure total nitrogen, carbon and ${ }^{13} \mathrm{C}$ enrichment. Mass spectrometry was conducted by the Australian Rivers Institute (Griffith University, Nathan, QLD, Australia) using an Isoprime Mass Spectrometer (GV Instruments, Manchester, UK) instrument with an EA 3000 inlet (Eurovector, Milan Italy). Protein content was calculated from particulate organic nitrogen using the protein-to-nitrogen conversion factor of $4.78( \pm 0.62)$, which has been determined from 12 species of phytoplankton, including 3 species of diatom (Lourenço et al., 2004). This approach is currently the most practical way of determining protein concentration, as it avoids uncertainties associated with extracting proteins from biomass, which can introduce substantial errors (Lourenço et al., 2004).

Carbon productivity was measured using the method described by Fernandez et al. (2005). Briefly, $\sim 100 \mathrm{ml}$ of culture from each replicate flask was transferred into a $250-\mathrm{ml}$ Erlenmeyer flask and $0.5 \mathrm{ml}$ of tracer solution $\left(3.64 \mathrm{mg}^{13} \mathrm{C} \mathrm{ml}^{-1}\right.$, which is equivalent to $0.5 \mu \mathrm{mol} \mathrm{ml}{ }^{-1}$ ) was added. Replicate cultures $(n=4)$ were incubated for $4 \mathrm{~h}$ under $50 \mu \mathrm{mol}$ photons per $\mathrm{m}^{2} \mathrm{~s}^{-1}$ of growth irradiance before microalgae were vacuum filtered onto pre-combusted GF/F filters, rinsed with isotonic saline solution and dried in an oven at $60^{\circ} \mathrm{C}$ overnight. Control samples were incubated in the dark for $4 \mathrm{~h}$ and natural background ${ }^{13} \mathrm{C}$ levels were measured in culture sub-samples taken before the addition of the tracer solution. Samples were stored under vacuum desiccation until analysis by mass spectrometry.

Carbon productivity was calculated from the level of ${ }^{13} \mathrm{C}$ enrichment relative to natural background levels following the equations in Fernandez et al. (2005). These mass spectrometry measurements were used as the calibration and validation data from which multivariate models of carbon productivity were created based on spectral data (see 'Multivariate modeling' below). Carbon content was taken as the total particulate organic carbon per unit DW (dry weight).

\section{Predictive model calibration and validation}

For samples from the $-1.8^{\circ} \mathrm{C}$ and $5^{\circ} \mathrm{C}$ treatments, mass spectrometry was used to generate a set of calibration data for cellular carbon, protein and carbon productivity (described above). Although mass spectrometry provides a robust measure of these variables, it has some limitations. For instance, the financial cost of each measurement is relatively high, the analysis can only be performed on bulk samples (not single cells within mixed populations) and the turnaround time is relatively long (generally days to weeks). These factors can limit the scope and scale of studies, representing a bottleneck in the collection of phytoplankton phenotypic data. To overcome this limitation, we used FTIR spectroscopy and multivariate modeling as a supplementary method to generate phenotypic data for a third treatment $\left(2{ }^{\circ} \mathrm{C}\right)$. The development of these models is described in this section.

Owing to the highly multivariate nature of spectroscopic data, partial least squares regression (PLSR) modeling was used to probe the data in more detail and predict phenomic parameters in 'unknown' independent samples (known as the validation set). The PLSR approach is useful for dealing with complicated data sets where univariate regression is difficult or impossible to apply. Since its first publication in 1966, the PLSR approach has become a standard tool in chemometrics (Wold et al., 2001; Barker and Rayens, 2003). In this study, PLSR models were built using the data generated through mass spectrometry to calibrate the spectroscopic data. Data from mass spectrometry were divided into two groups using a stratified-random method so that two-thirds of the data formed the calibration data set and the remaining third formed the independent validation test set. Replicates included in the calibration set were not included in the validation set. PLSR models were then built using the Unscrambler X 10.2 (CAMO) where each ' $\mathrm{Y}$ ' variable was the independently measured composition and productivity data (that is, protein, carbon and productivity) and each ' $\mathrm{X}$ ' variable was an infrared absorbance spectrum. In other words, to estimate the rate of carbon productivity from the spectrum of a single sample (that is, a single time point), a linear regression was created using PLSR modeling, to associate the spectral data with a rate of carbon productivity measured from multiple samples (that is, two time points) using mass spectrometry. The rate of carbon productivity of 'new' independent samples could then be predicted from samples taken at a single time point based on this PLSR model. Models were validated for robustness and accuracy of prediction for productivity, cellular carbon and protein concentration based on FTIR spectra of intact C. simplex cells grown under a range of salinity and temperature conditions.

The regions $3050-2800$ and $1540-1000 \mathrm{~cm}^{-1}$ were selected for analysis, as they contain all the major biological bands and avoided possible issues related to spurious absorbance values for the amide I band $\left(\sim 1650 \mathrm{~cm}^{-1}\right)$, owing to variability in background atmospheric water vapor, and differences in the levels of bound water within samples (Vaccari et al., 2012). Outliers were identified by inspecting the leverage and residual $\mathrm{X}$ and $\mathrm{Y}$ variance plots, with a threshold of $5 \%$ (set nominally). Additional regions of the spectrum were excluded (that is, 'feature selection') through a process of trial and error until each PLSR model was optimized (final spectral range included in the model was 30502800 and $1250-1000 \mathrm{~cm}^{-1}$ ). The models were validated using the test set data and summary statistics reported were based on the predictive performance of the models. 
Significance testing

Data from the different treatment conditions were compared by two-factor analysis of variance (for salinity and temperature), post-hoc Tukey's tests and a significance level of $\alpha=0.05$ (SigmaPlot 11.0 Systat, San Jose, CA, USA). Two-way analysis of variance for productivity failed the test of normality; thus, significance was calculated using the Scheirer-RayHare non-parametric test (Holmes et al., 2010).

\section{Results}

FTIR spectroscopy for macromolecular 'snapshot' Visual inspection of infrared spectra identified obvious changes in the macromolecular composition of $C$. simplex between treatments. In cells from all treatments, the average second derivative spectrum showed strong bands associated with unsaturated fatty acids $\left(3015 \mathrm{~cm}^{-1}\right)$, saturated $\mathrm{CH}$ stretches $(2960,2920$, $\left.2850 \mathrm{~cm}^{-1}\right)$, anti-symmetric phosphodiester vibrations $\left(\sim 1240 \mathrm{~cm}^{-1}\right)$, carbohydrates $\left(1155 \mathrm{~cm}^{-1}\right)$ and silicate/ silicic acid bands $\left(\sim 1076 \mathrm{~cm}^{-1}\right.$; Figure 1; see Table 1 for band assignments). Variation in absorbance intensity between treatments was particularly strong for bands associated with carbohydrates and silicate/ silicic acid, the dominant compounds in diatom frustules. Variation in cell spectra with salinity treatments was most obvious at $5^{\circ} \mathrm{C}$, where cell spectra from salinity levels 30 and 35 were notably different from those at the 55 and 70 levels (Figure 1c).

\section{Predictive model calibration and validation}

The PLSR model constructed for the prediction of carbon productivity is shown in Figure 2, as an example of the PLSR models constructed for cellular protein and carbon content. For carbon productivity, cell spectra clustered in PLSR scores plots by treatment conditions with $5^{\circ} \mathrm{C}$ treatments toward the top of the scores plot and $-1.8^{\circ} \mathrm{C}$ treatments toward the bottom (Figure 2a) along the direction of Factor 2. Cell spectra from lower salinity treatments tended to cluster toward the right and higher salinity toward the left. The loading weights plot indicated that variation between the cell spectra was multivariate, with contributions from regions associated with lipids and proteins ( 3015, 2960, 2920 and $\left.\sim 2850 \mathrm{~cm}^{-1}\right)$, phosphorylated molecules ( 1240 $\left.\mathrm{cm}^{-1}\right)$, carbohydrates $\left(\sim 1155 \mathrm{~cm}^{-1}\right)$ and silicate/ silicic acid $\left(\sim 1076 \mathrm{~cm}^{-1}\right.$; Figure $\left.2 \mathrm{~b}\right)$. Comparing the loading weights plot with the second derivative average spectra confirmed the absorbance from lipids in the region $2800-3000 \mathrm{~cm}^{-1}$ (Figure 1). The reference versus predicted plot (which shows ${ }^{13} \mathrm{C}$ measurements of carbon productivity versus values predicted by the spectroscopy-based model) showed a linear trend with cell spectra from higher salinity treatments clustering toward the left of the plot and lower salinity treatments toward the right along the direction of Factor 1 (Figure 2c). Cell

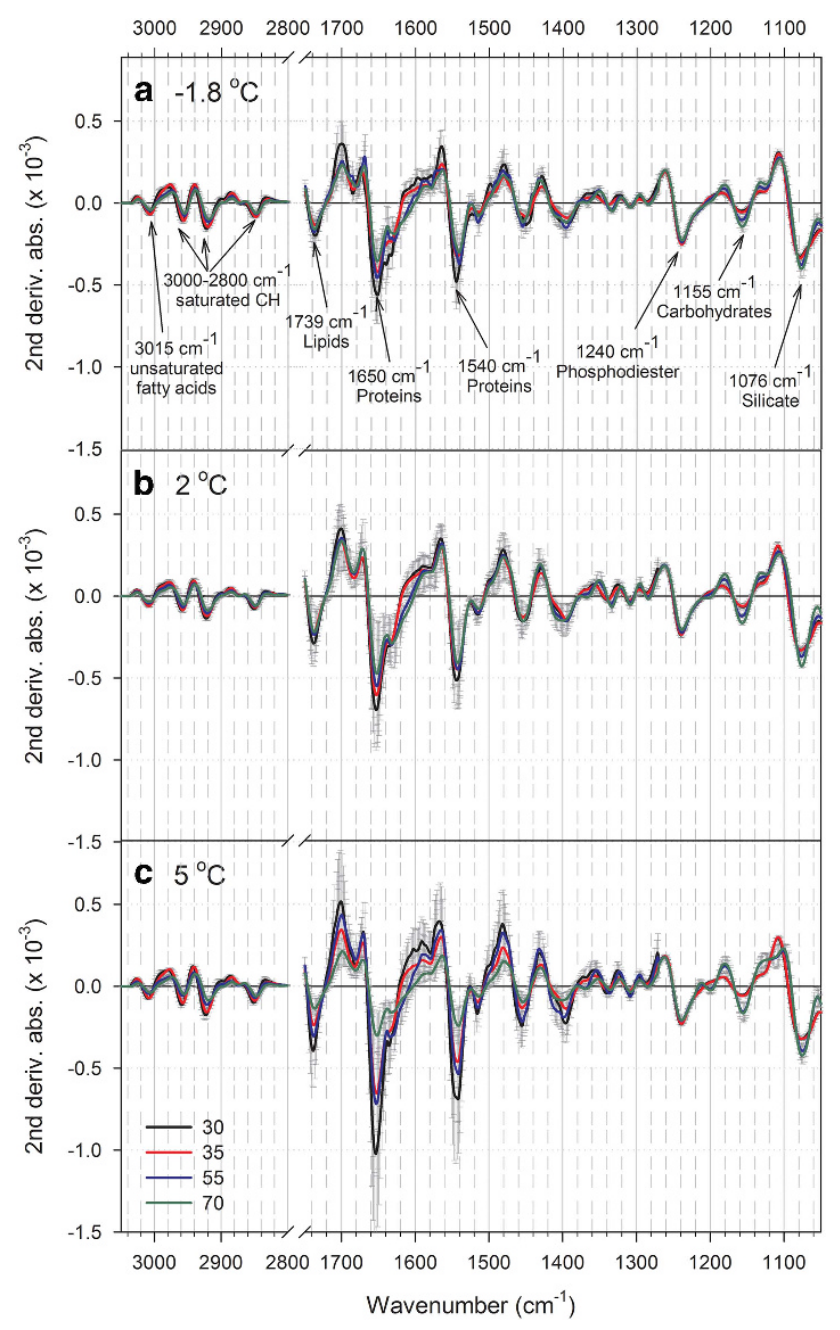

Figure 1 Average second derivative spectra (3000-2800 and $1270-1000 \mathrm{~cm}^{-1}$ ) for $C$. simplex under various temperature and salinity treatments. The sea-ice treatment is shown in green in plot (a), meltwater is shown in black on plot (b) and the pelagic is shown in red on plot (c). Bands related to lipids, proteins, carbohydrates and silicate/silicic acid are visible under all treatment conditions. Differences in the area bounded by the minima peaks and the ordinate axis correspond to differences in the concentration of associated macromolecules. Error bars indicate 1 s.d. from the mean.

spectra from the $-1.8^{\circ} \mathrm{C}$ temperature treatments clustered toward the left-hand side of the plot, whereas $5^{\circ} \mathrm{C}$ treatments occurred along the entire range of the plot. The predictive accuracy of all three models (carbon, protein and productivity) was relatively high. All models were linear and achieved $R^{2}$ values between 0.762 and 0.844 , with the root mean square error of the prediction ranging between $10 \%$ and $15 \%$ of the maximum $Y$-value (Table 2). The residual predictive deviation, which is often used to assess the quality of PLSR models, showed that all models presented were of 'Excellent' quality (residual predictive deviation $>8$; Table 2) (Williams and Norris, 2001).

Mass spectrometry data for treatments associated with $-1.8^{\circ} \mathrm{C}$ and $5^{\circ} \mathrm{C}$ are presented along with data 
Table 1 Infrared band assignments

\begin{tabular}{lll}
\hline Wavenumber $\left(\mathrm{cm}^{-1}\right)$ & Assignment & Reference and references therein \\
\hline $1200-900$ & $\nu(\mathrm{C}-\mathrm{O}-\mathrm{C})$ of polysaccharides, dominated by ring vibrations of carbohydrates & (Giordano et al., 2001; \\
& & Naumann, 2000) \\
$1070-1080$ & $\nu(\mathrm{Si}-\mathrm{O})$ from silicate/silicic acid & (Giordano et al., 2001) \\
1155 & $\mathrm{C}-\mathrm{O}$ vibrations of carbohydrates & (Stehfest et al., 2005) \\
1240 & $\nu_{\text {as }}$ Phosphodiester from nucleic acids and other phosphorylated molecules & (Vongsvivut et al., 2012) \\
$3000-2800$ & $\nu(\mathrm{C}-\mathrm{H})$ mainly from methyl groups from proteins and methylene groups from & (Coates, 2000) \\
3015 & saturated fatty acids & (Coates, 2000) \\
\hline
\end{tabular}

${ }^{\mathrm{a}} \nu_{\text {as }}$, asymmetric stretch; $\nu_{\mathrm{s}}$, symmetric stretch; $\delta$ as, asymmetric deformation (bend); $\delta$ s, symmetric deformation (bend).

predicted using PLSR models for treatments associated with $2{ }^{\circ} \mathrm{C}$ (Figure 3). The model results were obtained using spectroscopy-based predictive models, which were validated by mass spectrometry. By using FTIR spectroscopy as a supplement to mass spectrometry, we were able to increase the scope and improve the cost-effectiveness and turnaround time of our study. Primary productivity reached a maximum $(0.0018 \mathrm{~g} \mathrm{C}$ per g DW per $\mathrm{d}$ or $1.64 \pm 0.26 \mu \mathrm{g} \mathrm{Cl}^{-1}$ per day) in conditions similar to those found in the Southern Ocean pelagic habitats (salinity $\left.35,5^{\circ} \mathrm{C}\right)$ and a minimum $\left(7.9 \times 10^{-5} \mathrm{~g} \mathrm{C}\right.$ per $\mathrm{g}$ DW per d or $0.18 \pm 0.03 \mu \mathrm{C} \mathrm{Cl}^{-1}$ per day) in conditions representative of sea-ice habitats (salinity $70,-1.8^{\circ} \mathrm{C}$; Figure 3a). Productivity predictions for treatments associated with $2^{\circ} \mathrm{C}$ fell within the range of values measured for the $-1.8^{\circ} \mathrm{C}$ and $5^{\circ} \mathrm{C}$ treatments, with a moderate rate of production for cells in the simulated meltwater treatment (salinity $30,2^{\circ} \mathrm{C}$ ). Growth rates declined with increasing salinity, with doubling rates dropping from a maximum of 0.43 in the pelagic $\left(5^{\circ} \mathrm{C}\right.$, salinity 35 ) treatment to -0.11 at $5^{\circ} \mathrm{C}$ and salinity 35 ; Figure 3d). Cellular carbon content followed a similar trend to productivity, with a maximum measured in cells from the pelagic treatment and a minimum measured at a salinity level of 70 (sea-ice brine treatment) for both the $-1.8^{\circ} \mathrm{C}$ and $5^{\circ} \mathrm{C}$ treatments (Figure 3b). Carbon content predicted for treatments associated with $2^{\circ} \mathrm{C}$ fell within the range of values measured for the $-1.8^{\circ} \mathrm{C}$ and $5^{\circ} \mathrm{C}$ treatments. Cellular carbon and protein content showed a significant positive relationship with carbon productivity $\left(P<0.001\right.$ in both cases), with $R^{2}$-values of 0.765 and 0.743 , respectively (Table 3 ). In both cases, the standard error of prediction was about $10 \%$ of the maximum $Y$-value.

\section{Discussion}

This study measured multiple phenotypic traits from intact cells of $C$. simplex using both mass spectrometry and FTIR microspectroscopy. The limited acclimation period of $72 \mathrm{~h}$ was designed to probe the species responses to short-term fluctuations in temperature and salinity levels known to occur within the sea-ice matrix (Thomas and Dieckmann, 2002). The results showed that $C$. simplex cells from the pelagic treatment (salinity 35 and $5{ }^{\circ} \mathrm{C}$ ) had the highest cellular carbon, protein, energy content and the greatest rates of carbon production (Figures 3 and 4). This evidence suggests that $C$. simplex cells tolerated the cold temperatures and high salinities experienced during the short-term acclimation period; however, there was a cost associated with metabolic (reduced protein and carbon content) and physiological rates (reduced growth rate and productivity). In particular, all phenotypic traits consistently showed increased sensitivity toward high salinity irrespective of temperature, suggesting that salinity was the main driver behind phenotypic adjustment. These results suggest that $C$. simplex may experience reduced metabolic and physiological rates during short-term periods of high salinity and low temperature within sea-ice environments. Given further acclimation time, it is possible that increases in metabolic and physiological performance could have occurred; however, within the highly fluctuating seaice environment, the ability to rapidly adjust to short-term changes in salinity and temperature may be an important adaptive trait for sea-ice algae. As such, lower metabolic and physiological rates in response to high salinity and low temperature levels could also be consistent with the propensity of Chaetoceros species to form resting spores in sea-icedominated habitats (Armand et al., 2005).

Carbon productivity rates were highest in the pelagic and lowest in the sea-ice treatment (Figure 3c). This is consistent with the findings of Petrou and Ralph (2011), who also showed that the net primary productivity (inferred from oxygen evolution rates) in $C$. simplex was highest in pelagic and lowest in sea-ice conditions during short-term acclimation experiments. The results are also consistent with in-situ measurements from an Antarctic ice-covered lake (Priscu et al., 1998). Further, the $\sim 8$-fold difference in carbon productivity rates between cells from the sea-ice and pelagic treatments is almost identical to that measured by Boyd et al. (1995), where carbon productivity rates in sea-ice algae were eight times lower than those in the surrounding water column. Together, this evidence 


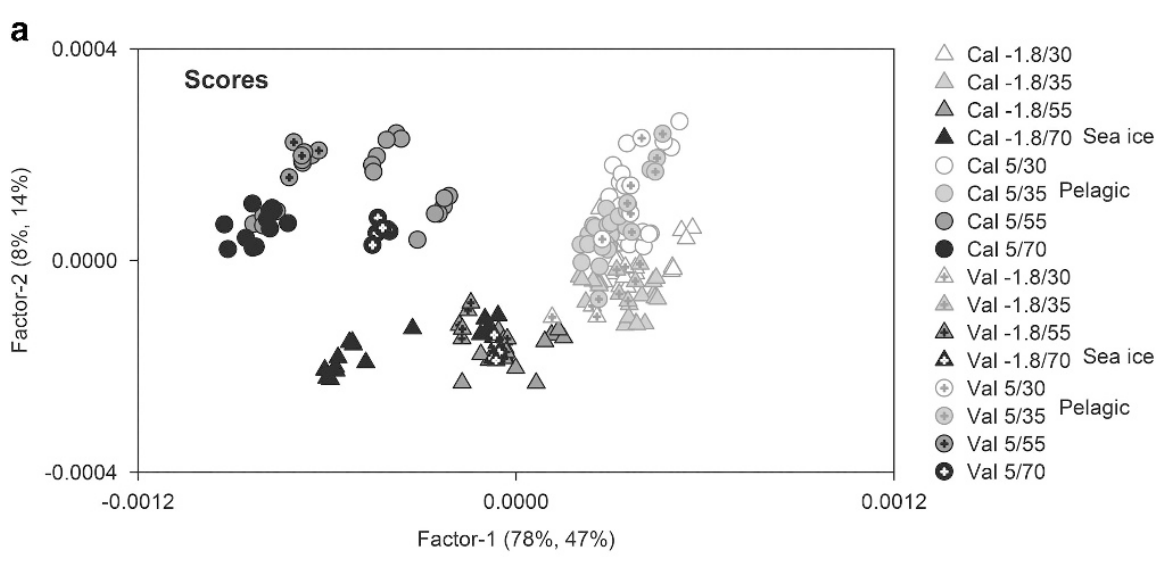

b
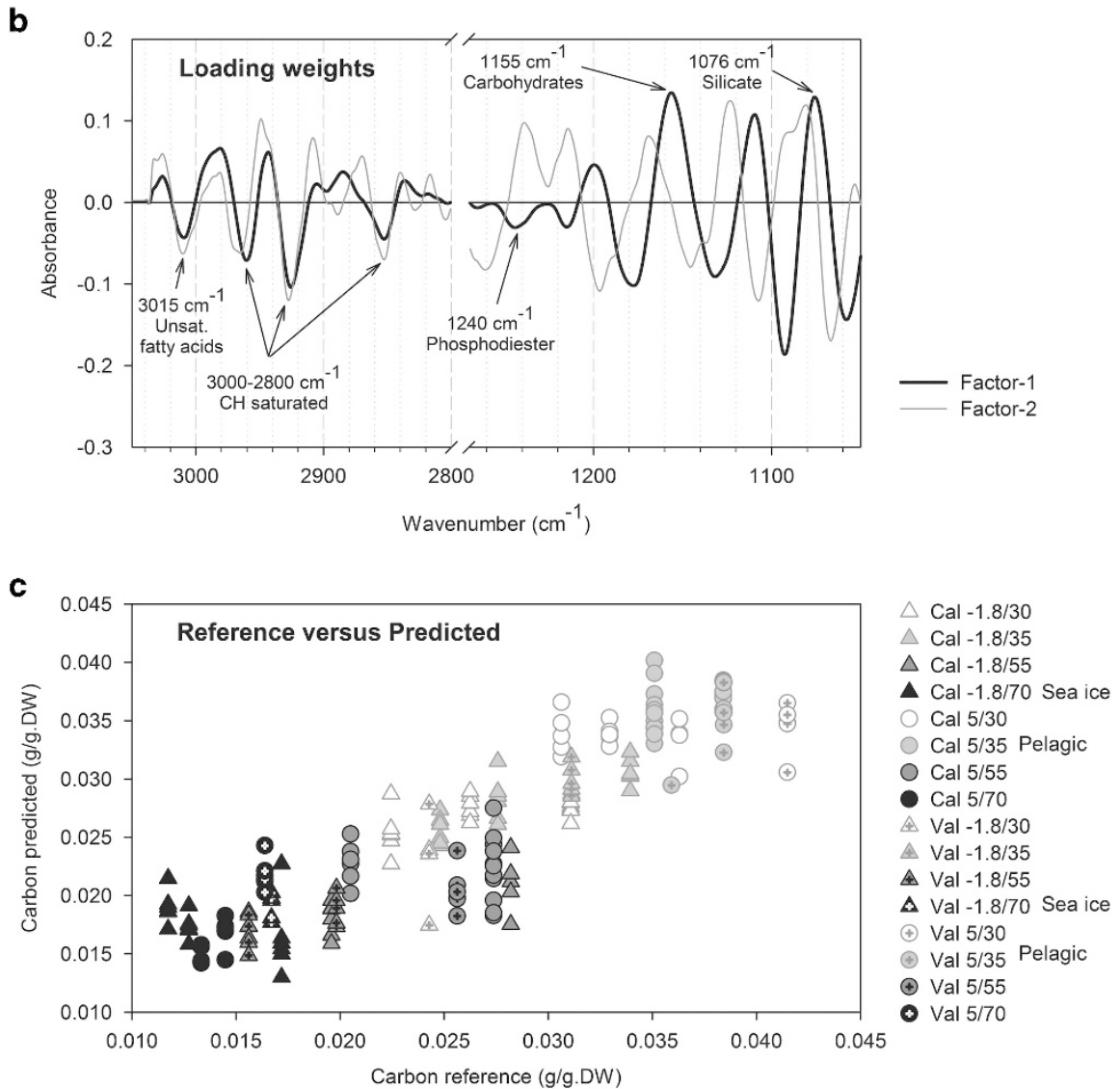

Figure 2 PLSR prediction model for cellular carbon productivity. The scores plot for Factors 1 and 2 (a) shows cell spectra from treatments with salinity 30, 35, 55 and 70 (black, dark grey, light grey and white, respectively), and $5{ }^{\circ} \mathrm{C}$ and $-1.8^{\circ} \mathrm{C}$ (circles and triangles, respectively). Independent validation samples are indicated by a cross hair in the center of the symbol. Loading weights associated with the Factor 1 and 2 scores are shown in $\mathbf{b}$. Validation results are shown as the reference versus predicted plot (c) and validation statistics are shown in Table 2.

provides strong support for the relevance of the 'snapshot' predicted values we obtained from our mass spectrometry-derived model.

Lower concentrations of cellular protein in sea-ice algae relative to phytoplankton have previously been reported for algal communities in Alaska (Lee et al., 2008). Consistent with these observations, we found that cellular protein, carbon and energy content, as well as productivity rates were lowest at the highest salinities (similar to those found in sea ice) irrespective of temperature treatments (Figures 3 and 4). Hypersaline conditions have been reported to strongly influence both photosynthetic efficiency (Ryan et al., 2004; Ralph et al., 2007) and growth rates (Aletsee and Jahnke, 1992). In contrast, temperature seemed to have less of an effect on the phenotypic response of $C$. simplex. Aletsee and Jahnke (1992) found that phytoplankton exhibited a greater tolerance to changes in temperature compared with salinity, observing no change in cellular 
Table 2 PLSR predictive model validation statistics

\begin{tabular}{lccc}
\hline Model & Protein & Carbon & Productivity \\
\hline Units & g per g DW & g per g DW & g C per g DW per d \\
$n$ (calibration) & 131 & 130 & 129 \\
$n$ (validation) & 53 & 53 & 53 \\
$n$ (prediction) & 60 & 60 & 60 \\
Factors & 5 & 5 & 5 \\
Pearson $R^{2}$ & 0.844 & 0.829 & 0.762 \\
Max Y-value & 0.0336 & 0.0415 & 0.0018 \\
RMSEP & 0.0038 & 0.0041 & 0.0003 \\
RMSEP/Max $Y$-value & $\pm 11 \%$ & $\pm 10 \%$ & $\pm 15 \%$ \\
RPD & 9.2 & 9.8 & 13.2 \\
Quality & Excellent & Excellent & Excellent \\
\hline
\end{tabular}

Abbreviations: RMSEP, root mean squared error of the prediction; $\mathrm{RPD}$, residual predictive deviation.

${ }^{a}$ Quality evaluation based on RPD; models with RPD $>8$ are

considered to be of 'Excellent' quality (Williams and Norris, 2001). protein content in cells grown in temperatures ranging from $-4^{\circ} \mathrm{C}$ to $3{ }^{\circ} \mathrm{C}$, a similar range to that used in this study.

Lipid accumulation in natural populations of sea-ice algae has been reported for communities in both the Antarctic and Arctic, and it has been suggested that these lipids may constitute an important source of high-energy biomass for organisms such as juvenile krill (Fahl and Kattner, 1993; Lee et al., 2008), a keystone species in the Southern Ocean ecosystem. Although cellular lipid concentrations in C. simplex cells in this study were found to be elevated $(\sim 10 \%)$ in the sea-ice treatment (see Sackett et al. (2013)), increased lipid concentrations were associated with a substantial drop (>50\%) in protein content (Figure 4). Although protein biomass embodies approximately half the caloric value of

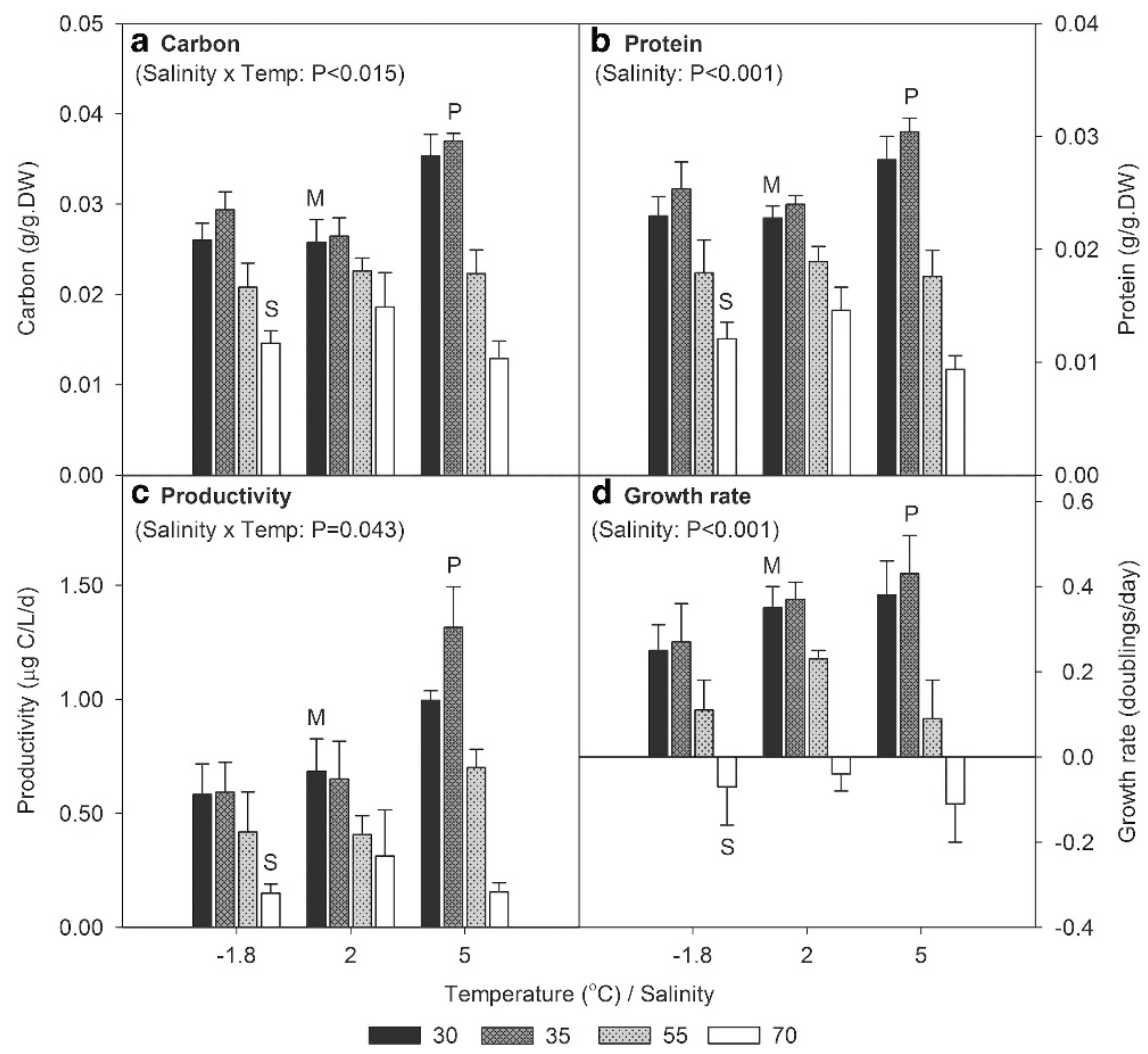

Figure 3 Carbon (g/g DW; a), protein (g/g DW; b), productivity ( $\mu \mathrm{g} \mathrm{Cl} \mathrm{l}^{-1}$ per day; $\mathbf{c}$ ) and growth rate (doublings/day; d) for C. simplex versus salinity and temperature treatments. Treatment characteristics of sea ice, meltwater and pelagic habitats are indicated by the letters 'S', 'M' and 'P', respectively. Text in brackets indicates the results of two-factor analysis of variance, where 'Salinity $\times$ Temp' refers to the interaction of the two factors. Error bars show the s.e.m.

Table 3 Nonlinear regression summary statistics for productivity versus carbon and protein

\begin{tabular}{lcccr}
\hline Phenotypic trait & Unit & Regression equation & P-value & $\mathrm{R}^{2}$ \\
\hline Carbon & g per g.DW & $y=0.0315+0.0087 \times \ln (x)$ & $<0.0001$ & 0.765 \\
Protein & g per g.DW & $y=0.0265+0.0074 \times \ln (x)$ & $<0.0001$ & 0.743 \\
\hline
\end{tabular}




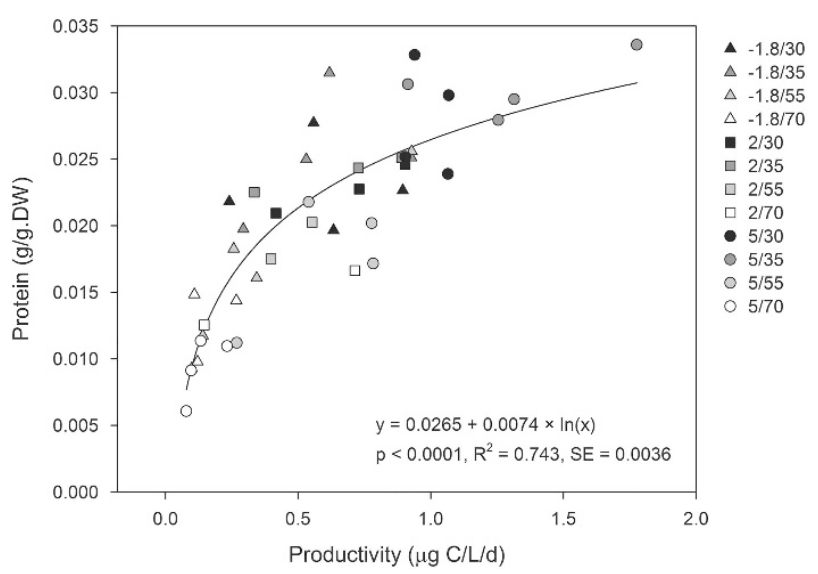

Figure 4 Carbon productivity ( $\mu \mathrm{Cl}^{-1}$ per day) versus protein (g per g.DW). Regression equations and statistics are shown in Table 3. Treatment characteristics of sea ice $(-1.8 / 70)$, meltwater $(2 / 30)$ and pelagic $(5 / 35)$ conditions are indicated in the legend.

lipid biomass (Whyte, 1987), it is likely to be that there was a net reduction in energy content of the biomass in the sea-ice-treated cells. The relationship between macromolecular composition and energy content in sea-ice algae thus deserves further investigation.

Previously, Sackett et al. (2013) found the lipid concentrations in Fragilariopsis cylindrus, a dominant Southern Ocean sea-ice diatom, were lower and protein concentrations higher than those found in C. simplex under the same simulated sea-ice conditions. Similarly, Petrou and Ralph (2011) showed species-specific photosynthetic sensitivity to simulated sea-ice and pelagic conditions, with F. cylindrus 'outperforming' C. simplex under sea-ice conditions. This suggests that variations in phenotypic plasticity, including photosynthesis, cellular energy content and associated changes in macromolecular composition are likely to be taxon specific. Consequently, shifts in phytoplankton assemblage composition have the potential to affect the amount of energy, carbon and protein available to higher trophic levels of the Southern Ocean food web. Together, this provides further evidence that the productivity and nutritional value of Southern Ocean phytoplankton communities may vary substantially with both habitat (for example, sea ice versus pelagic) and taxonomic composition (Figures 3 and 4).

In this study we were able to use a combined mass spectrometry-FTIR spectroscopy approach to obtain phenomic information on C. simplex under different salinity and temperature conditions. The results from the spectroscopic measurements of cultured algae were consistent with those obtained by other methods and from in-situ studies. The study provides insight into the phenotypic responses of $C$. simplex to short-term variations in temperature and salinity that occur within the sea-ice environment. Specifically, C. simplex is able to tolerate low temperatures, but experiences reduced carbon productivity and protein levels at high salinity, at least in the first $72 \mathrm{~h}$. As a consequence, this species is likely to represent a lower-quality food source if salinity conditions are highly variable along short temporal scales. Given the importance of sea-ice algae as a food source for the Southern Ocean ecosystem, the relationship between environmental change and the nutritional value of microalgae is worthy of further investigation.

Although predictive models based on cultured organisms may have limited applicability in the field, this limitation may be overcome by using the calibration data from cultures as a starting point, then progressively updating the calibration set with field data over time. In particular, NanoSIMS is capable of measuring carbon and other elements in individual cells, making the collection of taxonspecific productivity data from natural populations a real possibility. Further, it may turn out that models developed for groups of taxa (for example, genera) provide sufficiently accurate predictions of phenotypic parameters to avoid the need for species-specific models. The approach outlined here therefore shows utility for contributing to this important area of research through rapid, highthroughput phenotypic analysis of microalgae.

\section{Conflict of Interest}

The authors declare no conflict of interest.

\section{Acknowledgements}

We thank Dr Scarlett Trimborn or the identification of C. simplex by electron microscopy at the Alfred Wegener Institute for Polar and Marine Research. We thank Finlay Shanks at the Monash Centre for Biospectroscopy for continued instrument technical support. OS was supported by a UTS Doctoral Scholarship.

\section{References}

Aletsee L, Jahnke J. (1992). Growth and productivity of the psychrophilic marine diatoms Thalassiosira antarctica Comber and Nitzschia frigida Grunow in batch cultures at temperatures below the freezing point of sea water. Polar Biol 11: 643-647.

Andreeva A, Velitchkova M. (2005). Resonance Raman spectroscopy of carotenoids in Photosystem I particles. Biophys Chem 114: 129-135.

Armand LK, Crosta X, Romero O, Pichon J-J. (2005). The biogeography of major diatom taxa in Southern Ocean sediments: 1. Sea ice related species. Palaeogeogr Palaeoclimatol Palaeoecol 223: 93-126.

Arrigo KR. (2005). Marine microorganisms and global nutrient cycles. Nature 437: 349-355.

Barker M, Rayens W. (2003). Partial least squares for discrimination. J Chemom 17: 166-173.

Bassan P, Byrne H, Bonnier F, Lee J, Dumas P, Gardner P. (2009). Resonant Mie scattering in infrared 
spectroscopy of biological materials - understanding the 'dispersion artefact'. Analyst 134: 1586-1593.

Bassan P, Lee J, Sachdeva A, Pissardini J, Dorling KM, Fletcher JS et al. (2013). The inherent problem of transflection-mode infrared spectroscopic microscopy and the ramifications for biomedical single point and imaging applications. Analyst 138: 144-157.

Bernard KS, Steinberg DK, Schofield OME. (2012). Summertime grazing impact of the dominant macrozooplankton off the Western Antarctic Peninsula. Deep Sea Res Part I Oceanogr Res Pap 62: 111-122.

Blain S, Quéguiner B, Armand L, Belviso S, Bombled B, Bopp L et al. (2007). Effect of natural iron fertilization on carbon sequestration in the Southern Ocean. Nature 446: 1070-1074.

Boyd PW, Robinson C, Savidge G, Williams PJL. (1995). Water column and sea-ice primary production during Austral spring in the Bellingshausen Sea. Deep Res Part II Top Stud Oceanogr 42: 1177-1200.

Cao J, Ng ES, McNaughton D, Stanley EG, Elefanty AG, Tobin MJ et al. (2013). Fourier transform infrared microspectroscopy reveals that tissue culture conditions affect the macromolecular phenotype of human embryonic stem cells. Analyst 138: 4147-4160.

Carr M-E, Friedrichs MAM, Schmeltz M, Noguchi Aita M, Antoine D, Arrigo KR et al. (2006). A comparison of global estimates of marine primary production from ocean color. Deep Sea Res Part II Top Stud Oceanogr 53: $741-770$.

Charmantier A, McCleery RH, Cole LR, Perrins C, Kruuk LEB, Sheldon BC. (2008). Adaptive phenotypic plasticity in response to climate change in a wild bird population. Science 320: 800-803.

Coates J. (2000). Interpretation of Infrared Spectra, A Practical Approach. In: Meyers RA (ed), Encyclopedia of Analytical Chemistry, John Wiley \& Sons Ltd: Chichester, NH, USA, pp 10815-10837.

Dean A, Nicholson J, Sigee D. (2012). Changing patterns of carbon allocation in lake phytoplankton: an FTIR analysis. Hydrobiologia 684: 109-127.

Dean A, Sigee DC, Estrada B, Pittman JK. (2010). Using FTIR spectroscopy for rapid determination of lipid accumulation in response to nitrogen limitation in freshwater microalgae. Bioresour Technol 101: 4499-4507.

Diekmann ABS, Peck MA, Holste L St, John MA, Campbell RW. (2009). Variation in diatom biochemical composition during a simulated bloom and its effect on copepod production. J Plankton Res 31: 1391-1405.

Domenighini A, Giordano M. (2009). Fourier transform infrared spectroscopy of microalgae as a novel tool for biodiversity studies, species identification, and the asssessment of water quality. J Phycol 45: 522-531.

Ducklow HW, Fraser WR, Meredith MP, Stammerjohn SE, Doney SC, Martinson DG et al. (2013). West Antarctic Peninsula: an ice-dependent coastal marine ecosystem in transition. Oceanography 26: 190-203.

Fahl K, Kattner G. (1993). Lipid content and fatty acid composition of algal communities in sea-ice and water from the Weddell Sea (Antarctica). Polar Biol 13: 405-409.

Fernandez C, Raimbault P, Garcia N, Rimmelin P, Caniaux G. (2005). An estimation of annual new production and carbon fluxes in the northeast Atlantic Ocean during 2001. J Geophys Res 110: 1-15.
Field CB, Behrenfeld MJ, Randerson J, Falkowski P. (1998). Primary production of the biosphere: integrating terrestrial and oceanic components. Science 281: 237-240.

Filik J, Frogley MD, Pijanka JK, Wehbe K, Cinque G. (2012). Electric field standing wave artefacts in FTIR microspectroscopy of biological materials. Analyst 137: 853-861.

Giordano M, Heraud P, Beardall J, Al ET, Kansiz M, Heraud $\mathrm{P}$ et al. (2001). Fourier transform infrared spectroscopy as a novel tool to investigate changes in intracellular macromolecular pools in the marine microalga chaetoceros muellerii (bacillariophyceae) 1 fourier transform infrared (FT-IR) spectroscopy was used to study. J Phycol 37: 271-279.

Graff JR, Milligan AJ, Behrenfeld MJ. (2012). The measurement of phytoplankton biomass using flow-cytometric sorting and elemental analysis of carbon. Limnol Oceanogr Methods 10: 910-920.

Guillard RRL, Ryther JH. (1962). Studies of marine olanktonic diatoms: I. Cyclotella nana Hustedt, and Detonula confervacea (Cleve) gran. Can J Microbiol 8: 229-239.

Hama T, Miyazaki T, Ogawa Y, Iwakuma T, Takahashi M, Otsuki A et al. (1983). Measurement of photosynthetic production of a marine phytoplankton population using a stable 13C isotope. Mar Biol 73: 31-36.

Heraud P, Beardall J, McNaughton D, Wood B. (2007a). In vivo prediction of the nutrient status of individual microalgal cells using Raman microspectroscopy. Fems Microbiol Lett 275: 24-30.

Heraud P, Stojkovic S, Beardall J, McNaughton D, Wood BR. (2008). Intercolonial variability in macromolecular composition in P-starved and P-replete Scenedesmus populations revealed by infrared microscopy. J Phycol 44: 1335-1339.

Heraud P, Wood B. (2013). Editorial - the latest thinking and developments in optical diagnosis. Analyst 138: 3861-3862.

Heraud P, Wood B, Beardall J, McNaughton D. (2007b) Probing the influence of the environment on microalgae using infrared and raman spectroscopy. In: Kneipp K, Aroca R, Kneipp H, Wentrup-Byrne E (eds). New Approaches in Biomedical Spectroscopy. Vol. 963. American Chemical Society: Washington, DC, pp 85-106.

Heraud P, Wood BR, Tobin MJ, Beardall J, McNaughton D. (2005). Mapping of nutrient-induced biochemical changes in living algal cells using synchrotron infrared microspectroscopy. FEMS Microbiol Lett 249: 219-225.

Hessen DO, Agren GI, Anderson TR, Elser JJ, de Ruiter PC. (2004). Carbon sequestration in ecosystems: the role of stoichiometry. Ecology 85: 1179-1192.

Hirschmugl CJ, Bayarri ZE, Bunta M, Holt JB, Giordano M. (2005). Analysis of the nutritional status of algae by Fourier transform infrared chemical imaging. Infrared Phys Technol 49: 57-63.

Holmes D, Moody P, Dine D. (2010)Hypothesis testing: do my samples come from the same population? Non-parametric dataIn Research Methods for the Biosciences. Oxford University Press, pp 488.

Houle D, Govindaraju DR, Omholt S. (2010). Phenomics: the next challenge. Nat Rev Genet 11: 855-866.

Jebsen C, Norici A, Wagner H, Palmucci M, Giordano M, Wilhelm C. (2012). FTIR spectra of algal species can be 
used as physiological fingerprints to assess their actual growth potential. Physiol Plant 146: 427-438.

Krell A, Beszteri B, Dieckmann G, Glockner G, Valentin K, Mock T. (2008). A new class of icebinding proteins discovered in a salt-stress-induced cDNA library of the psychrophilic diatom Fragilariopsis cylindrus (Bacillariophyceae). Eur J Phycol 43: 423-433.

Lee SH, Whitledge TE, Kang S-H. (2008). Spring time production of bottom ice algae in the landfast sea ice zone at Barrow, Alaska. J Exp Mar Bio Ecol 367: 204-212.

Li M, Canniffe DP, Jackson PJ, Davison P, FitzGerald S, Dickman MJ et al. (2012). Rapid resonance Raman microspectroscopy to probe carbon dioxide fixation by single cells in microbial communities. ISME $J$ 6: 875-885.

Lourenço SO, Barbarino E, Lavín PL, Lanfer Marquez UM, Aidar E. (2004). Distribution of intracellular nitrogen in marine microalgae: calculation of new nitrogen-toprotein conversion factors. Eur J Phycol 39: 17-32.

Mock T, Hoch N. (2005). Long-term temperature acclimation of photosynthesis in steady-state cultures of the polar diatom Fragilariopsis cylindrus. Photosynth Res 85: $307-317$.

Mock T, Kroon BMA. (2002). Photosynthetic energy conversion under extreme conditions - II: the significance of lipids under light limited growth in Antarctic sea ice diatoms. Phytochemistry 61: 53-60.

Morgan-Kiss RM, Priscu JC, Pocock T, Gudynaite-Savitch L, Huner NPA. (2006). Adaptation and acclimation of photosynthetic microorganisms to permanently cold environments. Microbiol Mol Biol Rev 70: 222-252.

Naumann D. (2000). Infrared Spectroscopy in Microbiology. In: Meyers RA (ed), Encyclopedia of Analytical Chemistry, John Wiley \& Sons, Ltd.: West Sussex, UK, pp 102-131.

Nelson DM, Tréguer P, Brzezinski MA, Leynaert A, Quéguiner B. (1995). Production and dissolution of biogenic silica in the ocean: revised global estimates, comparison with regional data and relationship to biogenic sedimentation. Global Biogeochem Cycles 9: 359-372.

Petrou K, Doblin M, Ralph P. (2011). Heterogeneity in the photoprotective capacity of three Antarctic diatoms during short-term changes in salinity and temperature. Mar Biol 158: 1029-1041.

Petrou K, Ralph PJ. (2011). Photosynthesis and net primary productivity in three Antarctic diatoms: possible significance for their distribution in the Antarctic marine ecosystem. MEPS 437: 27-40.

Priscu JC, Fritsen CH, Adams EE, Giovannoni SJ, Paerl HW, Mckay CP et al. (1998). Perennial Antarctic lake ice: an oasis for life in a polar desert. Science 280: 2095-2098.

Ralph PJ, Ryan KG, Martin A, Fenton G. (2007). Melting out of sea ice causes greater photosynthetic stress in algae than freezing in. J Phycol 43: 948-956.

Ryan KG, Ralph P, McMinn A. (2004). Acclimation of Antarctic bottom-ice algal communities to lowered salinities during melting. Polar Biol 27: 679-686.

Sackett O, Petrou K, Reedy B, de Grazia A, Hill R, Doblin M et al. (2013). Phenotypic plasticity of Southern Ocean diatoms: key to success in the sea ice habitat? PLoS One 8: e81185.

Stehfest K, Toepel J, Wilhelm C. (2005). The application of micro-FTIR spectroscopy to analyze nutrient stress-related changes in biomass composition of phytoplankton algae. Plant Physiol Biochem 43: 717-726.

Thomas DN, Dieckmann GS. (2002). Antarctic sea ice-a habitat for extremophiles. Science 295: 641-644.

Vaccari L, Birada G, Grenci G, Pacor S, Businaro L. (2012). Synchrotron radiation infrared microspectroscopy of single living cells in microfluidic devices: advantages, disadvantages and future perspectives. J Phys Conf Ser 359: 012007.

Vongsvivut J, Heraud P, Zhang W, Kralovec JA, McNaughton D, Barrow CJ. (2012). Quantitative determination of fatty acid compositions in micro-encapsulated fish-oil supplements using Fourier transform infrared (FTIR) spectroscopy. Food Chem 135: 603-609.

Whyte JNC. (1987). Biochemical composition and energy content of six species of phytoplankton used in mariculture of bivalves. Aquaculture 60: 231-241.

Williams P, Norris K (eds). (2001). Implementation of near-infrared TechnologyIn Near-Infrared Technology in the Agricultural and Food Industries. American Association of Cereal Chemist: St. Paul, MN, USA, p 145.

Wold S, Sjöström M, Eriksson L. (2001). PLS-regression: a basic tool of chemometrics. Chemom Intell Lab Syst 58: 109-130.

Wood AM, Everroad R, Wingard L. (2005). Measuring growth rates in microalgal cultures. In: Andersen RA (ed). Algal Culturing Techniques. Elsevier Academic Press: San Diego, CA, USA, pp 269-286. 